\title{
Monophasic Action Potential. New Uses for an Old Technique
}

\author{
Adolfo A. Leimer, Idágene A. Cestari
}

\author{
São Paulo, SP - Brazil
}

Since the $18^{\text {th }}$ century, when Galvani introduced the concept of "animal electricity", electric potentials have been observed and recorded in different nerves and muscles, including hearts and isolated preparations of cardiac tissue.

It was observed that, when measuring the difference of potential between a small macerated cardiac area and an intact one, the injured region showed negativity in relation to the intact one (Fig. 1-A). The potential observed was named "injury potential". The existence of a cellular potential was inferred by measuring this injury potential. The probable explanation for the existence of this potential is that injury destroys the selective permeability of the cellular membrane, reducing the membrane's electrical resistance, allowing that an electrode placed in the injured region contacts the cellular cytoplasm through a fluid pathway of relatively low resistance ${ }^{1}$. This same term was later used in electrocardiography to designate a type of upslope of the ST segment, which referred, however, to a distinct phenomenon.

Using the injury potential method, researchers found that certain cells, classified as excitable, suffered sudden and transitory alterations in resting potential, with later return to the initial value (Fig. 1-B). This cycle was named cellular action potential.

In 1883, Burdon-Sanderson and Page ${ }^{2}$ obtained continuous recordings of the potentials generated by frog cardiac beats. In one of their observations, when an electrode was placed on the intact surface of the heart and another on an injured region, transitory monophasic potential (only one polarity) was recorded in opposition to the known transitory multiphase recordings (positive and negative polarities). This was the origin of the term monophasic action potential (MAP), whose form was very similar to the cellular action potential later obtained by the cellular impalement technique with microelectrodes (IT).

In the late $19^{\text {th }}$ century, it was already known that the electric currents generated in each cardiac beat could be

Instituto do Coração do Hospital das Clínicas - FMUSP

Mailing address: Adolfo A. Leirner - Rua Pernambuco 15, $4^{\circ}$ - 01240-020 - São Paulo, SP - Brazil detected on the surface of the body. This fact along with the discovery of the string galvanometer by Einthoven ${ }^{3}$ established, in the beginning of this century, electrocardiography as a viable clinical application. With the ability to measure the cardiac potentials on the surface of the body, electrophysiology was no longer practiced only in the laboratories, but began to have significant clinical applications. These recordings were usually multiphasic. In 1920, Mann ${ }^{4}$ introduced vectorcardiography (VCG), which was a two-dimensional vector loop. This invention extended to space the concepts of electrocardiography, which were then limited to the plane. Parallel to the discovery and use of surface multiphasic potentials, research on injury potentials for the study of the complete depolarization-repolarization (monophasic) cycle of the cardiac cell continued.

In the late 1930s, impaling the giant axon of the squid with electrodes became a powerful experimental resource providing the direct measurement of the electrical potential difference between the interior and the exterior of one single cell. In 1949, the cellular impalement technique was applied to the cardiac cell by Coraboeuf and Wiedmann ${ }^{5}$ and, in 1950 , by Woodbury et $\mathrm{al}^{6}$. Many of the theories developed for the giant axon of the squid could be applied to cardiac cells, elucidating the role of sodium ${ }^{5}$, potassium ${ }^{7}$, and calcium ${ }^{8}$ in heart function.

The significant theoretical findings provided by the cellular impalement method caused research on cardiac cellular potentials to focus on transmembrane measurements, thus interest in the old technique of the monophasic injury potential diminished.

In 1966, Korsgren et al ${ }^{9}$ used the works of Schutz ${ }^{10}$ (1931) to introduce a suction electrode that captured monophasic potentials with great simplicity, not requiring the production of a specific myocardial lesion, because this was already caused by the suction itself. In this way, the right ventricle MAP of a patient could be recorded, which revealed a clinical application for the technique of MAP recording. This pioneering work was improved by Olsson ${ }^{11}$, Olsson et al ${ }^{12}$, as well as by other researchers ${ }^{13,14}$, who refined the technique of the suction electrode and showed the usefulness of MAP recording in cardiac electrophysiology. Suction, however, presented the risks 


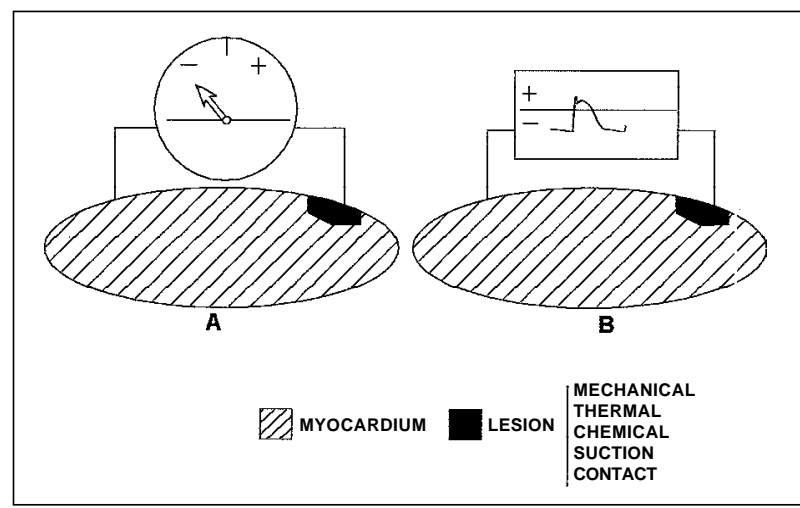

Fig. 1 - A) Sketch of the injury potential; B) Sketch of the action potential obtained through the injury technique.

of air embolism and irreversible mechanical myocardial lesion ${ }^{15}$. In 1986, Franz et al ${ }^{16}$, based on the observations of Jochim et al ${ }^{17}$ from 1934, produced an electrodecatheter (Fig. 2), which, with just simple contact with the myocardium, obtained a stable and high-quality MAP, eliminating the risks of suction. The MAP technique, which had been forgotten because of the impact of the transcellular measures, was once again considered a useful tool for experimental and clinical cardiac electrophysiology.

\section{Monophasic action potentials compared to transmembrane potentials and electrograms}

Briefly, in the second half of this century, cardiac electrophysiology depended on latu sensu electrograms, on in vitro transmembrane measurements taken in isolated cells and in the tissue of live animals, using monophasic injury potentials.

The latu sensu electrograms, which include the surface electrocardiogram (ECG) in all its variations and the intracavitary electrographic recordings, provide a distance view of the cardiac electric phenomena, because they represent the summation of the cellular electric activity of a

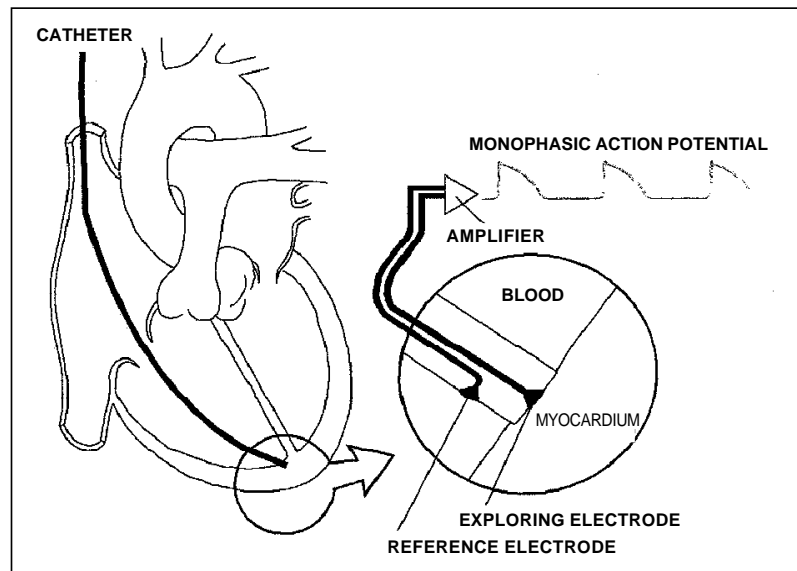

Fig. 2 - MAP catheter in right ventricle and sketch of the situation of the electrodes in relation to the myocardium. bigger or smaller cardiac area, depending on the technique used. What is actually obtained is the picture of action potentials distorted by their algebraic sum, dispersed in time and space and modified by the capacitances and resistances found in the way ${ }^{18}$. Electrograms hide cellular electrical phenomena during a great part of the cardiac cycle, when the absence of electrical gradients in the organ creates a real "electric silence" from a distance (Fig. 3). Mathematical models with dipoles and multipoles have been developed ${ }^{19}$; however, a well-defined relation between action potentials and electrograms lacks scientific basis. What we have are useful, but not so scientific, didactic attempts to relate action potentials to ECG in some situations ${ }^{20,21}$. In the diagnosis of anatomical, metabolic, ionic, and hemodynamic alterations, the use of electrograms was only possible because of innumerable empiric correlations. However, in regard to the moment of the occurrence of electrical events of the cardiac cycle, electrograms provide very precise and useful data, hence its fundamental importance in the diagnosis of arrhythmias.

Vectorcardiography, or simply VCG, is based on the simple dipole model, represented by a vector, using a system of three orthogonal axes that define three mutually perpendicular planes. The projection of the trajectory of this vector is drawn in relation to those axes, forming a loop display on an oscilloscope, in a cardiac cycle ${ }^{22,23}$. In ECG the important information is time and amplitude, in VCG it is magnitude and direction of propagation of the electromotive forces of the heart. In VCG, the relation between the graphic recordings and the action potentials is even more distant than in ECG.

In many situations, it is important to know in detail the entire temporal extension of cellular action potential. In such situations, two methods are left: the cellular impalement technique and the MAP method. For example, if we want to classify or study the action mechanism of an antiarrhythmic agent ${ }^{24,25}$, it is important to know the action potential in its

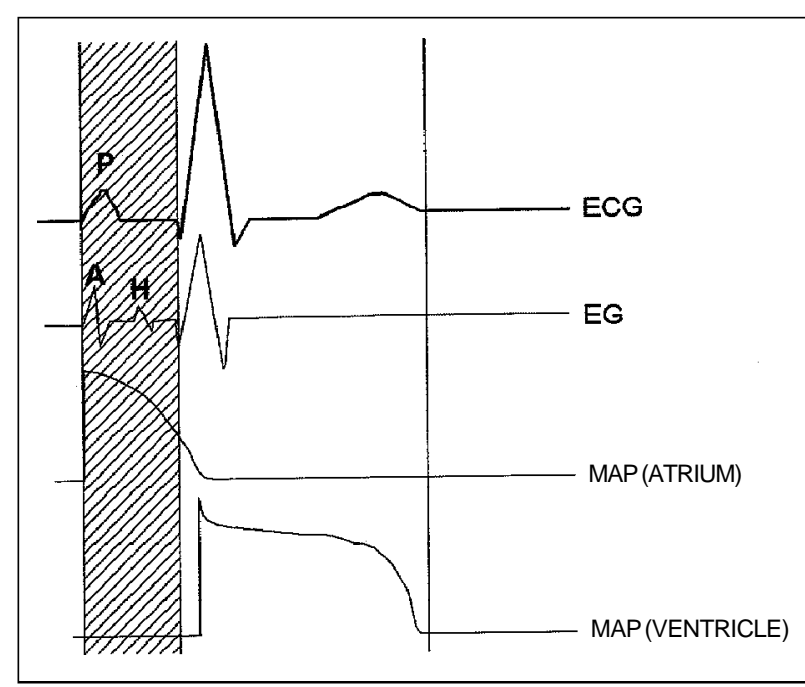

Fig. 3 - Sketch of the temporal relation between the electrocardiogram (ECG), the electrogram (EG) and the atrial and ventricular monophasic action potential (MAP). 
whole extension. In this and in many other cases, use of one of the above cited techniques is necessary.

The main advantage of MAP in relation to $\mathrm{IT}^{26}$ is the possibility of in vivo and in vitro endocardial and epicardial recordings in the intact heart, facilitating the exchange between the research laboratory and the clinical scenario. It also documents regional electrophysiological phenomena of the heart without interrupting the intrinsic organization of the tissue, and also documents the normal or pathological interrelations between the heart and the body.

As will be seen below, many times it is the only method for visualization of the action potential in situations where the observation must be made in an intact beating heart, in vivo or ex vivo.

Nevertheless, there are some disadvantages: MAP does not visualize the magnitude of the action and resting potentials, being useful only for morphological characterization and evolutional follow-up of the potentials; it does not provide accurate information about the rising time of the cellular action potential. The rising speed of MAP is around $10 \mathrm{~V} / \mathrm{s}$, while that measured by IT is around $200 \mathrm{~V} / \mathrm{s}$, showing that MAP consistently reflects the shape of phases 2,3 , and 4 of the cellular action potential, but not that of phases 0 and $1^{27,28}$. Unlike IT, MAP is a multicellular recording, providing a graphic recording that is a mean of the action potentials of many cells, covering a region of approximately $5 \mathrm{~mm}$ in diameter centered on the electrode. Therefore, it is not possible to guarantee that the measurements reflect homogeneous cell populations.

\section{Obtainment of the monophasic action potential}

The MAP signal is obtained by electrodes that should be in contact with the myocardium. Therefore, there are two types of electrodes: the epicardial and the endocardial. The application of the epicardial electrode (Fig. 4) requires direct contact with the epicardium and, consequently, needs a surgical incision for heart exposition. However, the endocardial electrode (Fig. 2) can be fixed to the extremity of a catheter and extended to the endocardium through vascular via, enabling its clinical utilization with a minimum risk to the patient.

The MAP signal captured by the electrode catheter should be amplified on a polygraph compatible with physiological signals and recorded for further analysis in a signal storing system, either analogical or digital (Fig. 5 and 6).

The MAP quantitative description can be performed through a large number of parameters. The most commonly adopted are $\mathrm{Vm}, \mathrm{t}_{20}, \mathrm{t}_{50}$ and $\mathrm{t}_{90}$, as shown in Figure 7.

Unlike ECG, MAP is a signal whose morphological alterations are frequently not very evident at visual examination. Only in certain cases does this examination provide evident data. One of the options is to measure the parameters above defined with a ruler and compass in order to characterize the measured potential, which can turn the method into a not so practical tool. To facilitate its application, we can use a specific software so MAP quantitative analysis can be automatically performed, providing several times and amplitudes. Figure 6 shows a series of MAPs after the analogicaldigital conversion using the acquisition and processing

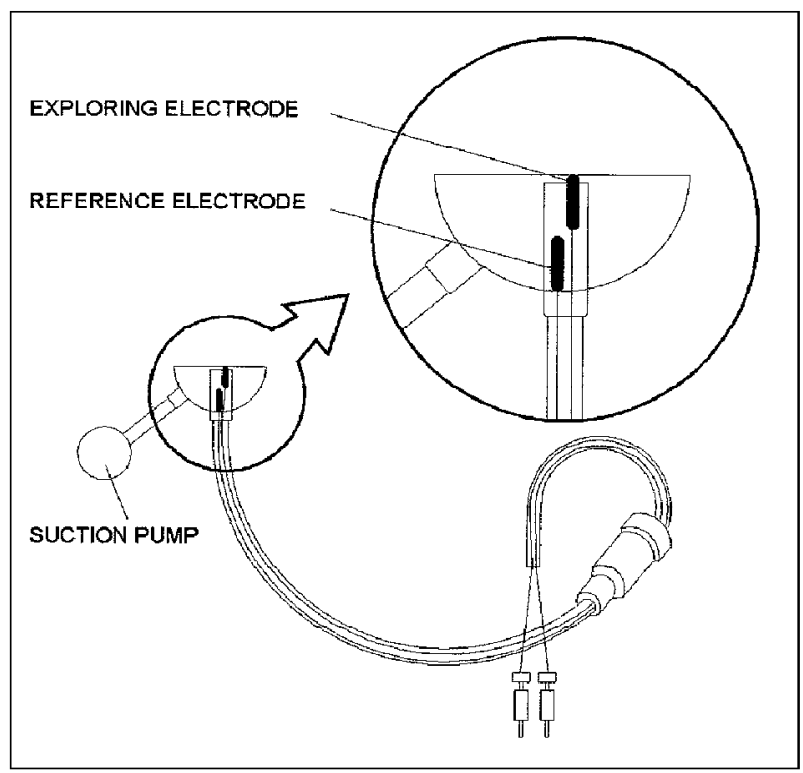

Fig. 4 - Sketch of the epicardial electrode for the MAP detection.

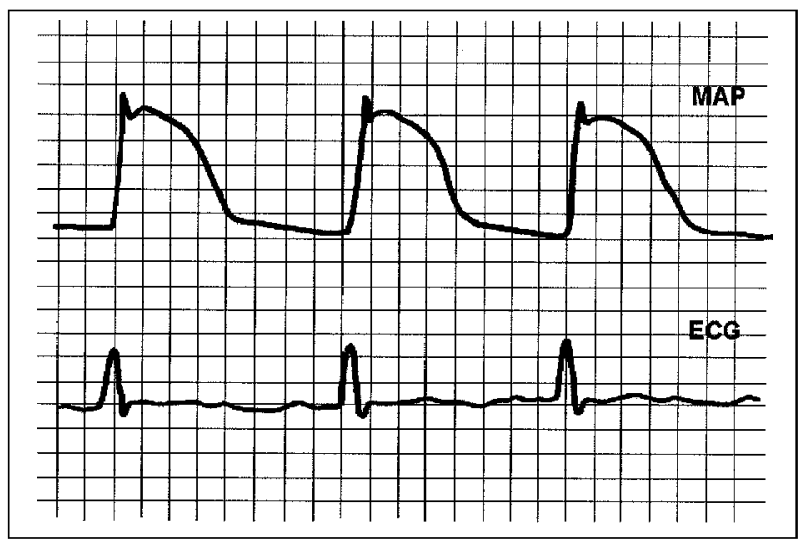

Fig. 5 - Analogical record of MAP obtained in a polygraph.

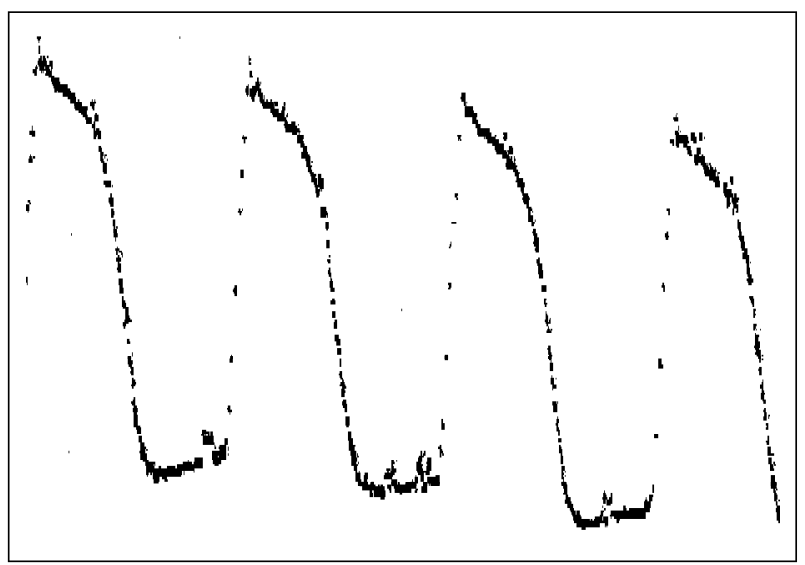

Fig. 6 - Illustration of the monophasic action potential after analogical-digital conversion. 


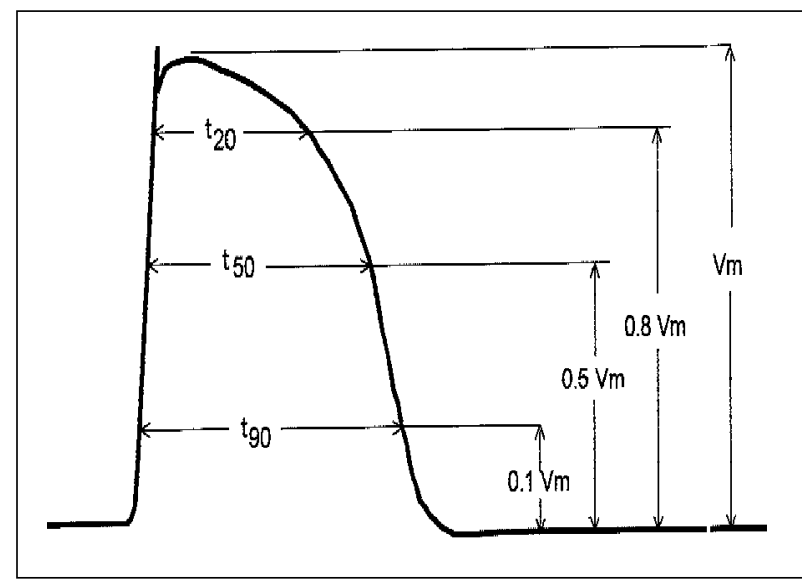

Fig. 7 - Explicatory diagram of the definitions of $\mathrm{t}_{20}, \mathrm{t}_{50}, \mathrm{t}_{90}$. The reference amplitude is represented by $\mathrm{Vm}$.

system developed at the Instituto do Coração, FMUSP (Medical School of São Paulo University) ${ }^{29}$. Table I shows the data automatically provided by the software after the analysis of the MAPs of figure 6 .

\section{Some examples of the use of the monophasic action potential method}

The following examples were chosen from among many existing reports in a large literature base and provide the researcher with applications of the method. Many applications will obviously be missing; however, they follow the basic principles cited below.

Relation between action potentials and electrocardiogram - The relations between action potentials and surface ECGs can be studied. Leirner ${ }^{29}$ experimentally determined a correction coefficient of the QT interval based on RR (dQT/dRR) using the MAP method and the observations of Franz et al ${ }^{30}$ that related the ECG $T$ wave characteristics to repolarization through the $t_{90}$ measurement.

\begin{tabular}{|c|c|c|c|c|c|}
\hline \multicolumn{6}{|c|}{$\begin{array}{l}\text { Table I - Data resulting from the analysis of } \\
\text { monophasic potentials. }\end{array}$} \\
\hline \multicolumn{6}{|c|}{ File: MAP } \\
\hline $\mathrm{P}\left(\mathrm{n}^{\mathrm{o}}\right)$ & $\mathrm{RR}(\mathrm{ms})$ & $\mathrm{dV} / \mathrm{dt}(\mathrm{V} / \mathrm{s})$ & T90(ms) & $\mathrm{T}_{50}(\mathrm{~ms})$ & $\mathrm{T}_{20}(\mathrm{~ms})$ \\
\hline 1 & 283,0 & 5,44 & 167,0 & 132,8 & 94,80 \\
\hline 2 & 305,4 & 5,56 & 164,6 & 132,2 & 89,80 \\
\hline 3 & 307,2 & 5,56 & 164,6 & 130,8 & 92,80 \\
\hline 4 & 289,0 & 5,69 & 164,8 & 132,6 & 95,00 \\
\hline 5 & 297,6 & 5,44 & 165,4 & 131,0 & 89,80 \\
\hline 6 & 303,2 & 5,62 & 163,8 & 131,4 & 90,20 \\
\hline 7 & 320,0 & 5,62 & 165,2 & 130,2 & 91,00 \\
\hline 8 & 287,6 & 5,56 & 165,8 & 131,6 & 95,00 \\
\hline 9 & 273,4 & 5,56 & 163,8 & 129,8 & 86,20 \\
\hline 10 & 305,0 & 5,44 & 165,2 & 131,4 & 91,40 \\
\hline Mean & 297,1 & 5,50 & 165,0 & 131,4 & 91,60 \\
\hline $\begin{array}{l}\text { Standard } \\
\text { deviation }\end{array}$ & 13,1 & 0,1 & 0,9 & 0,9 & 2,7 \\
\hline
\end{tabular}

Electrophysiology of the atrial muscle- $\mathrm{P}$ wave, which represents atrial contraction in ECG, provides poor information because it has a small amplitude and its repolarization is mixed in with the QRS complex. With MAP we can examine the atrial muscle action potential in its entire extension. Several aspects of the relation between atrial fibrillation (AF) and the action potential of the atrial cell were studied by Olsson et al ${ }^{31}$. These authors observed a short MAP in the atrium of patients with a tendency to repeated AFs after cardioversion. Olsson ${ }^{11}$ also observed a short atrial MAP in patients with hypothyroidism.

Arrhythmia - By the use of MAP, an association between the arrhythmias occurring in patients with the long QT syndrome and the anomalies of duration and temporal dispersion of their MAPs, as well as the presence of postpotentials ${ }^{32}$, was found. The possibility of postpotentials causing cardiac arrhythmias, as well as their appearance mechanisms, was largely studied with the aid of MAPs and summarized by Zipes ${ }^{33}$.

Antiarrhythmic drugs - The action of these drugs is related to the alterations they cause in the action potential of the cardiac cell, on which their classification is based ${ }^{24,25}$. Innumerable studies used the MAP to observe these alterations. To cite just one example, in a study of class III antiarrhythmic drugs, amiodarone showed the property of increasing the MAP duration of atrial cells ${ }^{34}$. The same type of reasoning can be used to study the action of electrolytic and acid-base imbalances in cardiac fiber and the genesis of arrhythmia.

Ischemia - MAP shape is much more sensitive than that of the electrogram in the detection of ischemia ${ }^{35}$. Considering this, several applications were proposed. In revascularization surgeries, Taggart et al ${ }^{36}$ evaluated the functional efficiency of by-passes using epicardial electrodes and detecting the ischemic alterations of MAP, when the by-pass blood flow was interrupted. Donaldson et al ${ }^{37}$ showed the great sensitivity of MAP to ischemic alterations during angioplasties.

Interaction between cardiac mechanics and action potential - We usually think of the electrical activity of the cardiac cell triggering the mechanical activity in a single direction. However, there is evidence of an inverse pathway; in other words, the mechanical activity could also cause changes in the electrical potential of the cells. This process was called excitation-contraction coupling or mechanoelectrical feedback ${ }^{38}$. Figure 8 shows the appearance of action potentials with early postpotentials in extrasystoles corresponding to cardiac beats, where the arterial pressure curve shows there was no significant ejection ${ }^{29}$. They can be considered as isovolumetric contractions against an infinite afterload, causing evident changes in the action potential.

Drug assessment and action mechanisms - This has been one of the most frequent uses of the MAP method. For example, Donaldson et al ${ }^{39}$ compared the effect of nitroglycerin on myocardial ischemia, through its systemic and local actions, 


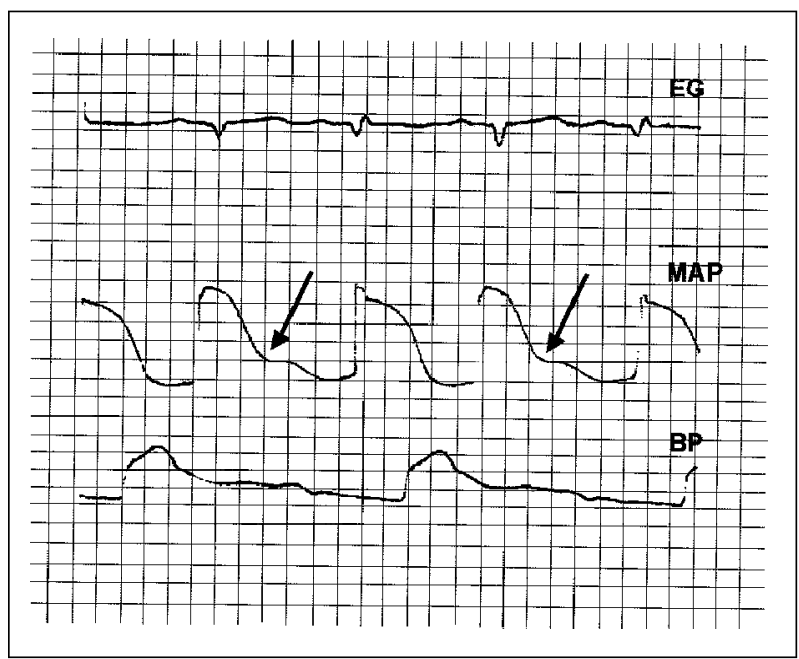

Fig. 8 - Alteration of the action potential due to mechanical solicitation (mechanoelectrical feedback). The arrows indicate the alteration of the repolarization curve in isovolumetric extrasystolic beats (modified from Leirner ${ }^{29}$ ). showing the importance of the first. This kind of experiment would never be possible in an isolated tissue or organ.

\section{Conclusion}

The monophasic action potential method represents a very useful and agile tool for the researcher in cardiology. Its main quality lies in the fact that it enables the study of the action potential of the cardiac fiber in vivo and, therefore, the study of the dynamic relation of this potential with all the organism variables. Moreover, it is of simple application and not expensive. The catheters can be commercially obtained or even manufactured in the laboratories without much difficulty. The capture and recording system does not differ from those used in the electrophysiology laboratories.

Among us, the application and interest in the MAP technique are only beginning ${ }^{29,40,41}$. MAP represents a valuable addition to the methodological set of tools available to those dedicated to research in cardiology.

\section{References}

1. Sperelakis N. Origin of the cardiac resting potential. In: Berne RM, et al - Eds Handbook of Physiology, The Cardiovascular System. Bethesda, Maryland: American Physiological Society, 1979: 188, 193, 211, 257.

2. Burdon-Sanderson J, Page FJM - On the electrical phenomena of the excitatory process in the heart of the frog and of the tortoise, as investigated photographically. J Physiol 1883; 4: 327-38.

3. Einthoven W, Fahr G, De Waart A - On the direction and manifest size of the variations of potential in the human heart and on the influence of the position of the heart on the form of the electrocardiogram. (Translated by Hoffel HE, Sekeley P. Pfluger's Arch f d Ges Physiol 1913; 150: 275-315) Am Heart J 1950; 40: 163-211.

4. Mann H - A method of analyzing the electrocardiogram. Arch Intern Med 1920; 25: 283-94.

5. Coraboeuf $\mathrm{E}$, Weidmann $\mathrm{S}$ - Potentials d'action du muscle cardiaque obtenus à l'aide de microeletrodes intracelulaires. Présence d'une inversion de potentiel. Car Soc Biol Paris 1949; 143: 1360-1.

6. Woodbury LA, Woodbury JW, Hecht HH - Membrane resting and action potentials from single cardiac muscle fibers. Circulation 1950; 1: 264-6.

7. Burgen ASV, Terroux KG - The membrane resting and action potentials of the cat auricle. J Physiol (Lond) 1953; 119: 139-52.

8. Orkand RK, Niedergerk R - Heart action potential. Dependence on external calcium and sodium ions. Science 1964; 146: 1176-7.

9. Korsgren M, Leskinen E, Sjostrand U, Varnauskas E - Intracardiac recordings of monophasic action potentials in human heart. Scand J Clin Lab Invest 1966; 18 : $561-4$.

10. Schutz E - Monophasische Aktionsstr̂̀ me vom in situ durchbluteten Säugetierherze. Klin Wschrm 1931; 10: 1454-7.

11. Olsson BS - Monophasic Action Potentials of Right Heart. Goteborg: Elanders, 1971.

12. Olsson B, Varnauskas E, Korsgren M - Further improved method for measuring monophasic action potentials of the intact human heart. J Electrocardiology 1971; 4: 19-23.

13. Shabetai R, Surawicz B, Hammil W - Monophasic action potentials in man. Circulation 1968; 38: 341-52.

14. Churney L, Oshima $\mathrm{O}$ - An improved suction electrode for recording from the dog heart in situ. J Appl Physiol 1964; 19: 793-8.

15. Olsson B - Right ventricular monophasic action potential during regular rhythm. Acta Med Scand 1972; 191: 145-57.

16. Franz MR, Burkhoff D, Spurgeon H, Weisfeldt ML, Lakatta EG - In vitro validation of a new cardiac catheter technique for recording monophasic action potentials. Eur Heart J 1986; 7: 34-41.

17. Jochim K, Katz LN, Mayne W - The monophasic electrogram obtained from the mammalian heart. Am J Physiol 1934; 111: 177-86.

18. Scher AM, Spach MS - Cardiac depolarization and repolarization and the electrocardiogram. In: Berne RM, Sperelakis N, Geiger SR, eds - Handbook of Physiology. Washington: Amer Physiol Soc, 1979: 357-92.

19. McFee R, Baule GM - Research in Electrocardiography and Magnetocardiography. Proc of the IEEE 1972; 60: 290

20. Kleeman K, Singh BN - Serum electrolytes and the heart. In: Maxwell MH, Kleeman CR, Narins RG, eds - Clinical Disorders of Fluid and Electrolyte Metabolism. $4^{\text {th }}$ ed. New York: McGraw-Hill, 1987.

21. Surawicz B, Saito S - Exercise testing for detection of myocardial ischemia in patients with abnormal electrocardiograms at rest. Am J Cardiol 1978; 14: 943.

22. Burger GCE, Klein G - Vector-Electrocardiography, Philips tech Rev 1959/ 1960; 1: 24.

23. Frank E - An accurate clinically practical system for spatial vectorcardiography. Circulation 1956; 13: 737.

24. Vaughan Williams EM - A classification of antiarrhythmic actions reassessed after a decade of new drugs. J Clin Pharmacol 1984; 24: 129.

25. Harrison DC - Antiarrhythmic drug classification: New science and practice applications. Am J Cardiol 1985; 56: 185.

26. Franz MR - Method and theory of monophasic action potential recording. Prog Cardiovasc Dis 1991; 33: 347-68.

27. Hoffman BF, Cranefield PF, Lepeschkin E, Surawicz B, Herrlich HC-Comparison of cardiac monophasic action potentials recorded by intracellular and suction electrodes. Am J Physiol 1959; 196(6): 1297-301.

28. Ino T, Karagueuzian HS, Hong K, Meesmann M, Mandel WJ, Peter T - Relation of monophasic action potential recorded with contact electrode to underlying transmembrane action properties in isolated tissues: a systematic microeletrode validation study. Cardiovasc Res 1988; 22: 255-64.

29. Leirner AA - Potencial de ação monofásico do músculo cardíaco - Sistema para obtenção e avaliação experimental (Tese de Doutorado). São Paulo: FMUSP, 1992: 52p.

30. Franz MR, Bargheer K, Costard-Jackle A, Craig Miller D, Lichtlen PR - Human ventricular repolarization and T wave genesis. Prog Cardiovasc Dis 1991: 23: 369-84.

31. Olsson SB, Cotoi S, Varnauskas E - Monophasic action potential and sinus rhythm stability after conversion of atrial fibrillation. Acta Med Scand 1971; 190: 381-7.

32. Gravilescu S, Luca C - Right ventricular monophasic action potentials in patients with long QT syndrome. Br Heart J 1978; 40: 1014-18.

33. Zipes DZ - Monophasic action potentials in the diagnosis of triggered arrhythmias. Prog Cardiovasc Dis 1991; 23: 385-96.

34. Olsson SB, Boronson L, Varnauskas E - Class 3 antiarrhythmic action in man. Observations from monophasic action potential recordings and amiodarone treatment. Br Heart J 1973; 35: 125-9.

35. Donaldson RM, Taggart $\mathrm{P}$, Swanton H, Fox K, Noble D, Rickards AF - Intracardiac electrode detection of early ischaemia in man. Br Heart J 1983; 50: 213-21. 
36. Taggart $\mathrm{P}$, Sutton $\mathrm{P}$, Runnalls $\mathrm{M}$, et al - Use of monophasic action potential recordings during routine coronary artery bypass surgery as an index of localized myocardial ischemia. Lancet 1986; 1462-5.

37. Donaldson RM, Taggart P, Bennet JG, Rickards AF - Study of electrophysiological ischemic events during coronary angioplasty. Texas Heart Institute Journal 1984; 11: 24-31.

38. Lab MJ - Monophasic action potentials and the detection and significance of mechanoelectric feedback in vivo. Prog Cardiovasc Dis 1991; 34: 29-35.

39. Donaldson RM, Taggart P, Swanton H, Fox K, Noble D, Rickards AF - Effect of nitroglycerin on the electrical changes of early or subendocardial ischaemia evaluated by monophasic action potential recordings. Cardiovasc Res 1984; 18: 7-13.

40. Fiorelli AI, Stolf NAG, Gaiotto F, et al - Detecção e análise do potencial de ação monofásico do miocárdio em pacientes com miocardiopatia e transplante cardíaco. Rev Bras Cir Cardiovasc 1997; 12: 260-8.

41. Scalabrini Neto A - Efeitos da solução hipertônica de cloreto de sódio (2400mOsm/L) sobre as alterações eletrofisiológicas causadas pela bupivacaína (Tese de Doutorado). São Paulo: Universidade de São Paulo, 1996: 57p. 